\title{
Foraging ecology of a generalist predator, the female New Zealand fur seal
}

\author{
Robert G. Harcourt ${ }^{1,2, *}$, Corey J. A. Bradshaw ${ }^{3}$, Kate Dickson ${ }^{1}$, Lloyd S. Davis ${ }^{1}$ \\ ${ }^{1}$ Department of Zoology, University of Otago, PO Box 56, Dunedin, New Zealand \\ ${ }^{2}$ Marine Mammal Research Group, Graduate School of the Environment, Macquarie University, Sydney, New South Wales \\ 2109, Australia \\ ${ }^{3}$ Antarctic Wildlife Research Unit, School of Zoology, University of Tasmania, PO Box 252-05, Hobart, Tasmania 7001, Australia
}

\begin{abstract}
This study examined how diet, foraging location and diving behaviour of female New Zealand fur seals Arctocephalus forsteri at Otago Peninsula, New Zealand (45 $\left.52^{\prime} \mathrm{S}, 170^{\circ} 44^{\prime} \mathrm{E}\right)$, varied in relation to prey abundance among seasons in 1994 and 1995. Time-depth recorders measured the diving behaviour of 24 lactating female fur seals, during summer, autumn or winter of 1994 and summer and autumn of 1995. Foraging locations were obtained by deploying satellite transmitters in summer, autumn and winter of 1994 only. Estimated biomass of prey items was determined from 690 scats and 166 regurgitates collected over summer, autumn and winter of both years, and compared with abundance data from research trawls in the same area. Foraging trip duration increased during the cooler seasons. Female fur seals showed a clear bout structure in dive behaviour, with the relative proportion of 3 main bout types (Long, Shallow, Deep) varying with season. Time between bouts (IBI) and bout duration varied with season, suggesting that prey distribution and prey encounter rate also varied. Linear discriminant analysis of the dive and foraging trip characteristics of individual females demonstrated clear seasonal differences. Females foraged on or near the continental slope in summer and farther offshore in autumn. Satellite telemetry locations and diet suggest principally inshore foraging during winter. Fur seals ate predominantly arrow squid Nototodarus sloanii during summer and autumn of both years, although fish, particularly myctophids, were persistent in the diet. Arrow squid were less common in winter when diet was more varied, and an inshore, benthic fish, ahuru Auchenoceros punctatus was dominant. There was no relationship between the annual changes in abundance of major prey species as measured by research trawls and their occurrence in seal diet. Overall, changes in dive behaviour may reflect changes in prey selection as prey abundance and availability change among seasons.
\end{abstract}

KEY WORDS: Fur seals - Diet - Dive behaviour - Dive bouts · Foraging trips - Satellite telemetry · Seasonal differences

Resale or republication not permitted without written consent of the publisher

\section{INTRODUCTION}

Animal foraging behaviour may be predicted to be in part a function of the abundance and distribution of food resources. In the marine environment, spatial and temporal changes in productivity mean that marked fluctuations in ocean habitat quality occur (Aebischer et al. 1990, White \& Peterson 1996). Higher predators

*E-mail: rharcour@ecosys.gse.mq.edu.au may show corresponding changes in foraging behaviour and spatial distribution in response to these fluctuations (e.g. seabirds: Croxall et al. 1988, Jouventin \& Weimerskirch 1990, Bost et al. 1997, Guinet et al. 1997; whales: Tynan 1998, Nicol et al. 2000; seals: Trillmich \& Ono 1991, McCafferty et al. 1998, Boyd 1999, Bradshaw et al. 2000, Georges et al. 2000a). Where there is an external constraint on spatial distribution, fluctuations in resources are most likely to result in changes in foraging activity (McCafferty et al. 1998). 
Female fur seals (Arctocephalus spp. and Callorhinus) are constrained to foraging relatively near to the breeding colony as they suckle their pup for long periods (4 mo to 3 yr depending on species), and the pup fasts while the mother is away at sea feeding. Females alternate periods of several days at sea with periods ashore suckling their pup, throughout lactation. When at sea, female fur seals are short, shallow divers that spend a large proportion of their time at sea near the surface (Harcourt et al. 1995, Boyd 1996). Therefore, their dive behaviour has been hypothesised to be an accurate reflection of foraging (Boyd 1996, Boyd \& Croxall 1996). Measurement of swimming speed has shown that at least for some species, surface activity includes both time travelling and periods when the seals are stationary at the surface and presumably resting (Ponganis et al. 1990, Boyd et al. 1995, Boyd 1996, Bonadonna et al. 2000). Therefore, it is thought that when fur seals dive they are either searching for prey or feeding successfully (Boyd 1996). This contrasts with the deeper-diving, large phocids that surface only to breathe, and for whom time under water encompasses not only foraging, but other activities such as travelling and resting (Fedak 1986, Le Boeuf et al. 1988, Hindell et al. 1991, Fedak \& Thompson 1993, Slip et al. 1994, Crocker et al. 1997). By inference, changes in the diving behaviour of fur seals should reflect changes in foraging activity, which may in turn reflect temporal and spatial variability in prey abundance.

Typically, fur seals dive, and therefore forage, in bouts or clusters of dives interspersed with periods at the surface (Gentry \& Kooyman 1986b, Boyd \& Croxall 1992, Boyd et al. 1994, Harcourt et al. 1995). Within bouts of dives, the surface interval between dives is relatively short. Dive bouts have been deemed to have ended when a significantly longer surface interval occurs, whether based on all of the surface intervals over a period at sea (Gentry \& Kooyman 1986a, Boyd \& Croxall 1992, Harcourt et al. 1995) or defined using some iterative technique based on previous surface intervals (e.g. Boyd et al. 1994, Harcourt et al. 2001). The intervals between bouts of dives are known as inter-bout intervals (IBIs) (Gentry \& Kooyman 1986a). Both the duration of dive bouts and the duration of IBIs have been related to the structure and dispersion of prey patches (Boyd 1996, Mori 1998). If, as proposed, dive bout duration reflects foraging behaviour, then the duration of a dive bout may be thought of as a corollary of the time a seal spends in a patch of prey. Therefore, the duration of a dive bout should be related to the size and density of a prey patch. Furthermore, intervals between dive bouts may reflect patterns of dispersion of prey types. Many species of oceanic prey are distributed patchily, and both dispersion and density of patches are highly variable (Veit et al. 1993, Kann \& Wishner 1995, Williams \& de la Mare 1995, Zamon et al. 1996). Predators require time to find prey patches, and the time spent searching for patches can be predicted to be a function of their availability (Stephens \& Krebs 1986).

Variance in the dive behaviour of Antarctic fur seals Arctocephalus gazella is correlated highly with prey patchiness, and so variation in IBI has been linked to fine- and meso-scale variation in prey availability (Boyd 1996). Antarctic fur seals foraging off Bird Island, South Georgia, feed primarily on krill Euphausia superba (Croxall \& Pilcher 1984, Reid 1995, Reid \& Arnould 1996), an animal that has a tendency to form small, compact swarms (Siegel \& Kalinowski 1994, Brierley \& Watkins 1997, Watkins \& Murray 1998). Boyd (1996) demonstrated that the time Antarctic fur seal females spent swimming between dive bouts matched dispersion of krill swarms and moreover, that time within patches increased in a year when food was less available.

Elsewhere in their range, Antarctic fur seals are for the most part less dependent on krill and feed predominantly on fish and cephalopod prey (e.g. South Shetland Islands: Daneri \& Carlini 1999; Kerguelen: Cherel et al. 1997; Marion Island: Klages \& Bester 1998; Macquarie and Heard Islands: Green et al. 1989, 1991, Goldsworthy et al. 1997). In general, this is true of most other species of fur seal (e.g. New Zealand fur seal Arctocephalus forsteri: Carey 1992, Fea et al. 1999; Australian fur seal A. pusillus doriferus: Gales et al. 1993; subantarctic fur seal A. tropicalis: Bester \& Laycock 1985, Goldsworthy et al. 1997, Klages \& Bester 1998, Ferreira \& Bester 1999; Galápagos fur seal A. galapagoensis: Dellinger \& Trillmich 1999; northern fur seal Callorhinus ursinus: Antonelis et al. 1997, Gentry 1998). For fur seals feeding on a variety of prey, alternative foraging patterns may arise depending on the particular prey species targeted. Many mesopelagic prey form aggregations at a range of spatial scales (Filin et al. 1990, Duhamel et al. 2000). We predict that fur seals foraging on abundant prey that form welldefined schools or swarms will behave similarly to Antarctic fur seals off South Georgia, with time spent in dive bouts corresponding to school density, and time between bouts corresponding to dispersal of patches. However, for disaggregated prey, or when there is a range of prey species available, dive patterns should not necessarily follow this same pattern. When feeding on a range of alternative prey, different search patterns should arise in accordance with shifts in target prey. Changes in dive behaviour may therefore reflect changes in presence or abundance of targeted prey.

In temperate female fur seals lactation lasts for 10 to 12 mo and throughout that period they must return frequently to feed their offspring (Trillmich 1990, Georges \& Guinet 2000). This limits how far they can venture 
from the natal colony for most of the year and as a result they may have to contend with seasonal changes in prey availability (Costa 1991). To date, there is limited information on the responses of fur seals with long lactation to seasonal fluctuations in prey abundance. Seasonal variation in diving behaviour has been reported for only 2 species, the subantarctic fur seal Arctocephalus tropicalis (Georges et al. 2000b) and the New Zealand fur seal A. forsteri (Mattlin et al. 1998). In neither of these studies was their diet quantified; rather, changes in diet were inferred from seal behaviour.

Therefore, in this paper we examine the foraging behaviour of the New Zealand fur seal in conjunction with information on diet composition and availability of prey. Dive characteristics of the females of this species have been described in detail (Harcourt et al. 1995, 2001, Harcourt \& Davis 1997, Mattlin et al. 1998). Females show the typical fur seal pattern of bouts of frequent short and relatively shallow dives (mean depth usually <100 m), at least in summer (Harcourt et al. 1995, 2001). Females are known to dive deeper in the cooler seasons, and it has been speculated that this is due to changes in the distribution and abundance of their prey (Harcourt \& Davis 1997, Mattlin et al. 1998). However, corresponding diet data have not so far been available. The New Zealand fur seal eats a broad range of prey species that vary in abundance both geographically and seasonally (Carey 1992, Dix 1993, Fea et al. 1999, Holborrow 2000). Given their limited foraging range $(<250 \mathrm{~km}$ from the breeding colony, Harcourt \& Davis 1997), changes in seasonal abundance of prey may be reflected in foraging behaviour. There is limited evidence that pup demand may influence foraging-attendance cycles under specific conditions (Arnould et al. 2001). However, the importance of pup demand and how it interacts with prey availability is unclear. Therefore, in this paper we have focussed on the foraging behaviour and prey resources exclusively.

Specifically, we compare the dive behaviour and diet of lactating female New Zealand fur seals in 3 seasons (summer, autumn, winter) of 1994 and 2 (summer, autumn) of 1995. We examine how dive behaviour varies with season, and we use satellite data from 1994 to assess whether the foraging areas are static or change among seasons. We also examine scats and regurgitates to determine if there are concurrent shifts in their diet among summer, autumn and winter of both years. Finally, we discuss our results in light of trawl survey data reflecting relative changes in potential prey availability during 1994 and 1995.

\section{MATERIALS AND METHODS}

Study site and capture methods. This study was done at Fuchsia Gully (Ohinepuha) $\left(45^{\circ} 52^{\prime} \mathrm{S}, 170^{\circ} 44^{\prime} \mathrm{E}\right)$,
Otago Peninsula, South Island, New Zealand, between 21 December 1993 and 28 August 1995. In summer (December to February), lactating female fur seals and their pups were captured either during the perinatal attendance period or shortly after their return from their first or second foraging trip following the procedures outlined in Harcourt et al. (1995). Summer foraging behaviour is described in detail in Harcourt et al. (1995, 2001). In autumn (April to May) of 1994 and 1995, and in winter (July to August) of 1994 only, further lactating female fur seals were captured and marked. Outside the breeding season the seals were more wary, and it was not possible to observe whether females were with pups immediately before capture. Therefore, the teats of these females were examined, and we assumed a female was suckling a pup if the teats were distended or expressed milk when manipulated. All females from which data were obtained were later seen to be suckling a pup.

Attendance patterns. The time ashore and the duration of foraging trips were calculated using the method outlined in Harcourt et al. (1995). The breeding colony was scanned systematically with binoculars twice daily between 07:50 and 09:15 $\mathrm{h}$ and between 16:00 and 17:00 h during summer, autumn and winter of 1994, and between 08:00 and 09:30 $\mathrm{h}$ during summer and autumn of 1995. A single sighting of a female at the breeding colony was deemed sufficient for her to be considered present at the colony on that day. The duration of foraging trips was determined by comparing the wet/dry periods recorded by the TDRs (see below) and corroborated by observations at the colony.

Dive behaviour and foraging locations. To measure the dive behaviour of female fur seals, Time-depth recorders (Mk 4 or Mk 6, Wildlife Computers, Woodinville, WA) were attached to all captured females as described in Harcourt et al. (1995, 2001) (Table 1). Satellite transmitters (PTTs) (Telonics ST6 $300 \mathrm{~mW}$ output, Telonics, Mesa, AZ) were also attached to females in summer, autumn and winter of 1994. The method used and a sub-sample of the locations received in summer and autumn have been reported in 2 earlier papers (Harcourt et al. 1995, Harcourt \& Davis 1997). PTTs were attached simultaneously with Mk4 TDRs to females $\left(\mathrm{n}_{\text {summer }}=2, \mathrm{n}_{\text {autumn }}=3, \mathrm{n}_{\text {winter }}=2\right)$. The dive behaviour of the females carrying PTTs was not discernibly different from females with TDRs only (see Harcourt et al. 1995, Harcourt \& Davis 1997).

Diet. Prey composition in summer, autumn and winter of 1994 was re-calculated from data published earlier by our group (Fea et al. 1999). For 1995, fresh scats and regurgitates were collected from the study site in summer, autumn and winter. Prey items were identified and a diet was reconstructed using the method outlined in Fea et al. (1999). Fish prey size was deter- 
Table 1. Mean attendance at the rookery and foraging trip length $(\mathrm{d} \pm \mathrm{SE})$ assessed observationally for summer, autumn and winter 1994 and summer and autumn 1995

\begin{tabular}{|lccccc|}
\hline Season & Summer 1994 & Autumn 1994 & Winter 1994 & Summer 1995 & Autumn 1995 \\
\hline Number of females & 18 & 25 & 23 & 29 & 17 \\
Number of attendances & 109 & 53 & 23 & 178 & 77 \\
Mean attendance (d) & $3.1 \pm 0.4$ & $1.9 \pm 0.2$ & $1.48 \pm 0.1$ & $2.0 \pm 0.2$ & $1.8 \pm 0.2$ \\
Number of foraging trips & 112 & 65 & $11.8 \pm 1.2$ & $3.6 \pm 0.4$ & $7.6 \pm 0.9$ \\
Mean foraging trip (d) & $3.4 \pm 0.2$ & $7.6 \pm 0.5$ & & 7.9 \\
\hline
\end{tabular}

mined using the equations reported in Table 1 in Fea et al. (1999), and cephalopods using equations from Tate (1981).

Relative abundance of prey. Abundance of prey items in the local region was calculated using data from a time series of National Institute for Water and Atmospheric Research (NIWA) trawls for continental shelf, edge and slope marine species off the southeastern coast of the South Island New Zealand (NIWA, Greta Point, New Zealand). The surveys use a 2-phase, stratified random trawl design, with 3 depth ranges (30 to 100, 100 to 200 and 200 to $400 \mathrm{~m}$ ) corresponding to inshore, shelf-edge and continental slope (Beentjes 1995). These depths correspond to the known foraging range and depth of New Zealand fur seals (Harcourt et al. 1995, Harcourt \& Davis 1997, Mattlin et al. 1998). Data used in the analysis were from trawls that occurred within a $200 \mathrm{~km}$ radius of Fuchsia Gully.

Data analysis. Records from each TDR were analysed as described in detail in Harcourt et al. (2001) using an iterative statistical technique modified from Boyd et al. (1994). Minimum foraging bouts were defined as 3 dives of $\geq 10 \mathrm{~m}$ depth within 20 min (Harcourt et al. 2001). Once a minimum bout was recognised, the upper $95 \%$ confidence limit of the mean surface interval was calculated and compared to the next surface interval in the dive series. If this surface interval was less than the upper confidence limit, that dive was included in the bout and the confidence limit was re-calculated. If the next surface interval was greater than the re-calculated confidence limit, then the bout finished (Harcourt et al. 2001). The number of bouts generated was not sensitive to choice of minimum bout time (15 vs $20 \mathrm{~min}$ ) or confidence limit ( $\alpha=0.01$ vs $\alpha=0.05$ ) (Harcourt et al. 2001). Therefore, to facilitate comparison with earlier studies, we chose a minimum bout period of $20 \mathrm{~min}$ and the confidence level of $\alpha=$ 0.05 for all bout groupings. We also tested whether the bout groupings differed significantly from random sampling by using an iterative Monte Carlo approach (Manly 1997a). We used FASTCLUS (SAS Institute Inc., Cary, NC) to categorise bouts based on standardised mean bout parameters (see Harcourt et al. 2001). FASTCLUS carries out a disjoint cluster analysis on the basis of Euclidean distances. We used a randomisation chi-square test (Manly 1997a) in the package RT 2.1 (Manly 1997b) to test for differences in the proportion of bouts between seasons.

We used a linear discriminant analysis (LDA) in SYS$\mathrm{TAT}^{\circledR}$ to determine differences in the diving behaviour of females among seasons (1994), and between summer and autumn (1995). The LDA was used to classify females according to individual characteristics, specifically, mass, foraging trip length and dive parameters (mean dive depth, mean dive duration, mean bottom time, mean descent rate and mean ascent rate), and then to identify the source of the separation of these groups.

As in Boyd (1996), time spent in dive bouts were assumed to represent time in prey patches, and the interbout interval (IBI) assumed to represent time spent swimming between patches. As we had few surface velocity measurements, we assumed that New Zealand fur seals have similar swim speeds to congeneric Antarctic fur seals $\left(1.8 \mathrm{~m} \mathrm{~s}^{-1}\right)$ and would therefore take a similar period of time when swimming between patches (Boyd et al. 1995). To estimate prey density and dispersion of prey, we compared the distribution of IBIs among seasons (see Boyd 1996). The frequency with which seals may encounter prey patches was defined as the inverse of the mean IBI, assuming that bouts of dives equate to successful foraging on a patch, and time between bouts equates to time searching for patches. IBIs > 720 min were excluded to account for seals resting all day (Harcourt et al. 1995). If prey patches are distributed randomly, then the encounter rate should follow a Poisson distribution, and we tested this using the 1-sample Kolmogorov-Smirnov test. We used a log survivorship curve of cumulative IBIs to determine whether there was more than 1 distribution (Martin \& Bateson 1986). Patch encounter rates were defined using IBIs greater than this inflexion point, assuming that shorter IBIs reflected variance in density within a patch.

\section{RESULTS}

\section{Attendance behaviour}

Female foraging trips were significantly shorter in the summer of both 1994 and 1995 compared to the 
cooler seasons (1-way ANOVA; 1994: $F_{2,46}=47.589$, $\mathrm{p}<0.001 ; 1995: F_{1,45}=25.27, \mathrm{p}<0.001$; Table 1). As with other fur seals, most foraging trips by females lasted several days (Table 1). However, in the summers of both 1994 and 1995, and in autumn 1995, females also left the colony for short (i.e. $<12$ h) foraging trips (classified as overnight foraging trips [OFTs] by Goldsworthy 1999). Only 1 OFT was seen in 1994 (earlier described in Harcourt et al. 1995). In summer 1995, $41 \%$ (9 out of 13) of the foraging trips by females with TDRs were less than $12 \mathrm{~h}$, and in autumn, $21 \%$ (3 out of 14).

\section{Dive characteristics}

In 1994, dive records were obtained from 4 females in summer, 6 in autumn, and 4 in winter. In 1995, records were obtained from 6 in summer and 5 in autumn. Dates of deployment, female mass, number of dives and mean dive depths are given in Table 2 .

The number of dives allocated to bouts using the above criteria varied from 39.1 to $93.5 \%$ (mean $=66.4$ $\pm 2.1 \%$ ) among all individuals (Table 3). With the exception of 3 females (FS294s, FS894a and FS595s), most individuals demonstrated significant clustering of bouts (Table 3). Although bout structure was apparent in both years and all 3 seasons, there were significant differences among seasons in the relative duration of bouts and inter-bout intervals (IBIs). In the summer of both years, IBIs were significantly shorter than dive bouts (except FS294s and FS595s, which did not show bout structure, and FS195s in which IBIs were random relative to bout duration). Therefore, time spent diving within bouts was longer than time spent either resting or travelling between patches.

In autumn, some females (2 in 1994 and 1 in 1995) showed similar bout structure to summer with short IBIs relative to bout duration (Table 3 ), but this pattern was not consistent across all females. Either the other seals showed no consistent relationship between IBI and bout duration or, in the case of FS795a, IBIs were significantly greater than bout duration (Table 3). For those females where the statistic P(DIB) (i.e., the probability that the number of dives in bouts generated from a random ordering of the dive sequence) was $>0.05$ or $<0.95$ (Harcourt et al. 2001), IBIs were random with respect to bout duration (Table 3).
We only have dive data for the winter of 1994. In winter 1994, bout structure was maintained, but differed in its temporal form relative to other seasons. IBIs were either long relative to bout length or not significantly different from bout length (Table 3 ).

The cluster analysis returned 3 bout types, and the characteristics of these dive types are shown in Table 4. Dive Bout Type 1 consists of long bouts, with medium duration and depth dives, hereafter Long bouts. Dive Bout Type 2, are short bouts, with few, short and shallow dives, hereafter Shallow. Dive Bout Type 3 are medium duration bouts with few, long and deep dives, hereafter Deep. Descent rates were consistently higher than ascent rates for all bout types. We used a chisquared test of proportions with 1000 randomisations (Manly 1997b) to test for the effect of season. All randomisations were significantly greater than the null-hypothesis chi-square, and the total probability was $<0.05$, suggesting that bout type did differ significantly between seasons (Fig. 1). In the summer of 1994 and 1995, and also in autumn of 1995, Shallow was the most common bout type (47 to $56 \%$ ), followed by Long and Deep. In autumn of 1994, Deep was the most common bout type (47\%), followed by Shallow; Long was (marginally) the least common. The proportion of bout types in winter was almost diametrically opposed to that of the summers and autumn 1995, and less than $17 \%$ of

Table 2. Female fur seals with TDR records for 1994 (summer, autumn and winter) and 1995 (summer and autumn). An asterisk denotes the female also carried a PTT. Date $=$ date of capture $(\mathrm{dd} / \mathrm{mm} / \mathrm{yy})$; dives $=$ number of dives; $\mathrm{DD}=$ dive depth

\begin{tabular}{|lllrrrr|}
\hline ID & \multirow{2}{*}{ Year } & \multirow{2}{*}{ Season } & Date & Mass $(\mathrm{kg})$ & Dives & Mean DD \pm SE $(\mathrm{m})$ \\
\hline FS194s & \multirow{2}{*}{1994} & \multirow{2}{*}{ Summer } & $23 / 12 / 93$ & 44.0 & 2022 & $19.2 \pm 0.4$ \\
FS294s & & & $23 / 12 / 93$ & 28.0 & 2796 & $14.2 \pm 0.2$ \\
${ }^{*}$ FS394s & & & $25 / 12 / 93$ & 37.5 & 2319 & $20.2 \pm 0.4$ \\
${ }^{*}$ FS494s & & & $29 / 12 / 93$ & 39.0 & 1840 & $18.6 \pm 0.5$ \\
FS594a & \multirow{2}{*}{1994} & \multirow{2}{*}{ Autumn } & $06 / 04 / 94$ & 35.0 & 3955 & $33.9 \pm 0.5$ \\
FS694a & & & $06 / 04 / 94$ & 42.0 & 3246 & $69.9 \pm 1.1$ \\
${ }^{*}$ FS794a & & & $06 / 04 / 94$ & 43.5 & 3001 & $48.8 \pm 0.8$ \\
${ }^{*}$ FS894a & & & $26 / 04 / 94$ & 45.5 & 2169 & $52.0 \pm 0.8$ \\
${ }^{*}$ FS994a & & & $26 / 04 / 94$ & 41.5 & 2443 & $36.7 \pm 0.7$ \\
FS1094w & 1994 & \multirow{2}{*}{ Winter } & $21 / 06 / 94$ & 40.0 & 2954 & $27.7 \pm 0.5$ \\
${ }^{*}$ FS1194ww & & & $21 / 07 / 94$ & 41.5 & 1822 & $65.1 \pm 1.4$ \\
FS1294w & & & $21 / 07 / 94$ & 37.0 & 2282 & $27.7 \pm 0.7$ \\
${ }^{*}$ FS1393w & & & $21 / 07 / 94$ & 45.0 & 3787 & $39.5 \pm 0.7$ \\
FS195s & \multirow{2}{*}{ Summer } & $10 / 01 / 95$ & 40.0 & 3318 & $29.3 \pm 0.4$ \\
FS295s & & & $10 / 01 / 95$ & 41.0 & 1543 & $29.1 \pm 0.8$ \\
FS395s & & & $10 / 01 / 95$ & 39.5 & 2782 & $28.5 \pm 0.5$ \\
FS495s & & & $10 / 01 / 95$ & 33.5 & 3016 & $24.2 \pm 0.5$ \\
FS595s & & & $01 / 02 / 95$ & 44.5 & 853 & $27.7 \pm 1.0$ \\
FS695s & & & $01 / 02 / 95$ & 41.5 & 1424 & $30.4 \pm 0.7$ \\
FS795a & \multirow{2}{*}{1995} & \multirow{2}{*}{ Autumn } & $13 / 04 / 95$ & 44.5 & 4553 & $20.5 \pm 0.3$ \\
FS895a & & & $13 / 04 / 94$ & 45.0 & 3644 & $36.4 \pm 0.5$ \\
FS995a & & & $12 / 05 / 95$ & 38.0 & 2050 & $20.3 \pm 0.5$ \\
FS1095a & & & $12 / 05 / 95$ & 41.0 & 2139 & $23.4 \pm 0.5$ \\
FS1195a & & & $12 / 05 / 95$ & 39.0 & 862 & $53.9 \pm 1.4$ \\
\hline
\end{tabular}


Table 3. Bout groupings per individual female. $\mathrm{P}(\mathrm{B})=$ probability the number of bouts generated from a random ordering of dives exceeds that generated from the true order. When $\mathrm{P}(\mathrm{B})$ is $<0.05$ or $>0.095$, dives occurred in bouts. $\mathrm{P}(\mathrm{DIB})=$ probability the number of dives in bouts (DIB) generated from a random ordering of dives exceeds that generated from the true dive order. When $\mathrm{P}(\mathrm{DIB})<0.05$, IBIs < bout duration, when $\mathrm{P}(\mathrm{DIB})>0.095$, IBIs $>$ bout duration

\begin{tabular}{|c|c|c|c|c|c|c|c|}
\hline ID & Year & Season & Bouts & DIB & $\%$ DIB & $\mathrm{P}(\mathrm{B})$ & $\mathrm{P}(\mathrm{DIB})$ \\
\hline FS194s & 1994 & Summer & 101 & 1073 & 53.1 & 0.982 & 0.008 \\
\hline FS294s & & & 159 & 1498 & 53.6 & 0.115 & $<0.001$ \\
\hline${ }^{*} \mathrm{FS} 394 \mathrm{~s}$ & & & 114 & 1403 & 60.5 & $>0.999$ & $<0.001$ \\
\hline${ }^{*} \mathrm{FS} 494 \mathrm{~s}$ & & & 78 & 719 & 39.1 & 0.003 & $<0.001$ \\
\hline FS594a & 1994 & Autumn & 290 & 2615 & 66.1 & $>0.999$ & 0.007 \\
\hline FS694a & & & 308 & 2605 & 80.3 & $>0.999$ & 0.754 \\
\hline${ }^{*}$ FS794a & & & 234 & 2199 & 73.3 & $>0.999$ & 0.011 \\
\hline${ }^{*}$ FS894a & & & 204 & 1756 & 81.0 & 0.991 & 0.086 \\
\hline${ }^{*}$ FS994a & & & 225 & 1636 & 67.0 & 0.816 & 0.196 \\
\hline FS1094w & 1994 & Winter & 297 & 2762 & 93.5 & $>0.999$ & 0.486 \\
\hline${ }^{*} \mathrm{FS} 1194 \mathrm{w}$ & & & 131 & 1061 & 58.2 & $>0.999$ & 0.691 \\
\hline FS1294w & & & 150 & 1552 & 68.0 & $>0.999$ & 0.120 \\
\hline${ }^{*}$ FS1393w & & & 243 & 2147 & 56.7 & $>0.999$ & 0.548 \\
\hline FS195s & 1995 & Summer & 279 & 2482 & 74.8 & $>0.999$ & 0.204 \\
\hline FS295s & & & 105 & 988 & 64.0 & 0.999 & 0.015 \\
\hline FS395s & & & 174 & 2047 & 73.6 & $>0.999$ & $<0.001$ \\
\hline FS495s & & & 195 & 1959 & 65.0 & $>0.999$ & $<0.001$ \\
\hline FS595s & & & 76 & 627 & 73.5 & 0.933 & 0.005 \\
\hline FS695s & & & 105 & 970 & 68.1 & $>0.999$ & 0.067 \\
\hline FS795a & 1995 & Autumn & 308 & 2605 & 57.2 & $>0.999$ & $>0.999$ \\
\hline FS895a & & & 317 & 2885 & 79.2 & $>0.999$ & 0.609 \\
\hline FS995a & & & 119 & 1126 & 54.9 & $>0.999$ & 0.014 \\
\hline FS1095a & & & 141 & 1332 & 62.3 & $>0.999$ & 0.526 \\
\hline FS1195a & & & 56 & 545 & 63.2 & $>0.999$ & 0.156 \\
\hline
\end{tabular}

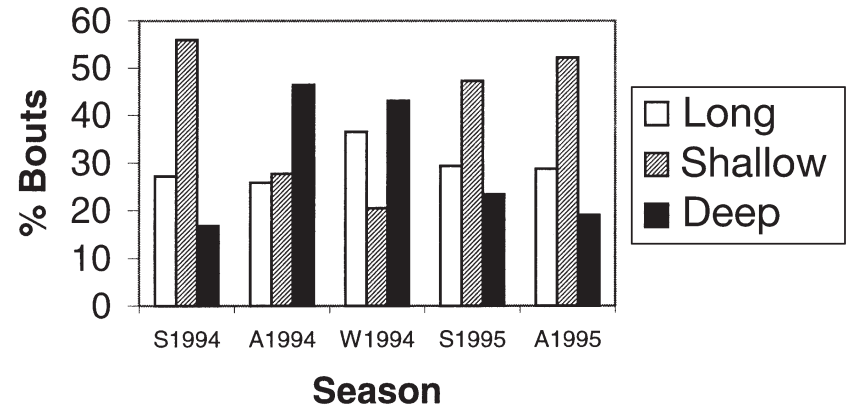

Fig. 1. Proportion of dive bout types by season for female fur seals for summer (S1994), autumn (A1994) and winter (W1994) of 1994 and summer (S1995) and autumn (A1995) of 1995 bouts were Shallow. Instead, Long and Deep were predominant (36 and $43 \%$ respectively).

The seasonal differences inferred from the change in proportions of dive bout type extend to the whole suite of dive characteristics of females. The linear discriminant analysis on individual characteristics revealed a clear separation in diving behaviour among seasons (Fig. 2). There was significant separation among the 3 seasons in $1994\left(F_{8,14}=11.8, \mathrm{p}<0.001\right)$, with $94 \%$ of the difference among seasons explained by the first canonical variable. There was a larger separation between summer and winter versus autumn and winter $\left(F_{4,7}=43.1\right.$ vs $F_{4,7}=8.2$; Fig. 1a). Here, trip duration $\left(F_{4,7}=9.0\right)$ and descent rate $\left(F_{4,7}=8.5\right)$ accounted for the majority of the difference in dive behaviour among seasons, with the other 5 variables making low contri-

Table 4. Dive bout characteristics (mean $\pm \mathrm{SE}$ ) for each cluster type. $\mathrm{DD}=$ dive depth; BDUR = bout duration; Dives $=$ number of dives; MDDUR = mean dive duration; MSURF = mean surface interval; MBOTT = mean bottom time; MDESC $=$ mean descent rate; $\mathrm{MASC}=$ mean ascent rate

\begin{tabular}{|lccccccccc|}
\hline Cluster & $\mathrm{n}$ & $\begin{array}{c}\mathrm{DD} \\
(\mathrm{m})\end{array}$ & $\begin{array}{c}\text { BDUR } \\
(\mathrm{min})\end{array}$ & $\begin{array}{c}\text { Dives } \\
(\mathrm{min})\end{array}$ & $\begin{array}{c}\text { MDDUR } \\
(\mathrm{min})\end{array}$ & $\begin{array}{c}\text { MSURF } \\
(\mathrm{min})\end{array}$ & $\begin{array}{c}\text { MBOTT } \\
\left(\mathrm{m} \mathrm{s}^{-1}\right)\end{array}$ & $\begin{array}{c}\text { MDESC } \\
\left(\mathrm{m} \mathrm{s}^{-1}\right)\end{array}$ & $\begin{array}{c}\text { MASC } \\
\text { Long }\end{array}$ \\
\hline Shallow & 1314 & $41.4 \pm 0.7$ & $45.43 \pm 0.91$ & $17.6 \pm 0.37$ & $1.99 \pm 0.02$ & $0.96 \pm 0.02$ & $0.87 \pm 0.02$ & $1.22 \pm 0.01$ & $1.16 \pm 0.02$ \\
Deep & 1425 & $20.7 \pm 0.2$ & $7.96 \pm 0.1$ & $6.0 \pm 0.07$ & $1.15 \pm 0.01$ & $0.58 \pm 0.01$ & $0.42 \pm 0.01$ & $1.13 \pm 0.01$ & $1.06 \pm 0.01$ \\
& 1425 & $72.8 \pm 0.9$ & $16.81 \pm 0.24$ & $5.4 \pm 0.05$ & $2.74 \pm 0.02$ & $1.21 \pm 0.02$ & $1.14 \pm 0.02$ & $1.48 \pm 0.01$ & $1.34 \pm 0.01$ \\
\hline
\end{tabular}


Table 5. Prey patch encounter rate (number of prey patches encountered $\mathrm{h}^{-1}$, IBI $>10 \mathrm{~min},<720 \mathrm{~min}$ ) with upper and lower $95 \%$ confidence limits, and coefficient of dispersion for summer, autumn and winter 1994 and summer and autumn 1995

\begin{tabular}{|lccccc|}
\hline Season & $\begin{array}{c}\text { Encounter } \\
\text { rate }(\text { prey } \\
\text { patches h }\end{array}{ }^{-1}$ ) & $\begin{array}{c}\text { Lower 95\% } \\
\text { confidence } \\
\text { limit }\end{array}$ & $\begin{array}{c}\text { Upper 95\% } \\
\text { confidence } \\
\text { limit }\end{array}$ & $\mathrm{n}$ & $\begin{array}{c}\text { Coefficient } \\
\text { of } \\
\text { dispersion }\end{array}$ \\
\hline Summer 1994 & 2.50 & 2.23 & 2.77 & 123 & 0.59 \\
Autumn 1994 & 2.54 & 2.36 & 2.72 & 364 & 0.69 \\
Winter 1994 & $2.01^{\mathrm{a}}$ & 1.81 & 2.21 & 286 & 0.87 \\
Summer 1995 & 2.65 & 2.41 & 2.88 & 205 & 0.65 \\
Autumn 1995 & $2.06^{\mathrm{a}}$ & 1.85 & 2.28 & 266 & 0.85 \\
a Significantly lower than the other 3 seasons & & & \\
\hline \multicolumn{5}{l}{} \\
\hline
\end{tabular}

winter 1994, intermediate in autumn 1995 and highest in the 2 summers $\left(\right.$ ANOVA, $F_{4,1239}=7.406, \mathrm{p}<0.001$, Table 5). The coefficient of dispersion for the encounter rate was $<1$ in each season, suggesting prey patches were significantly over-dispersed (Table 5).

\section{Foraging locations in 1994}

Locations at sea were obtained in 1994 only. Females appeared to forage much farther from the breeding colony in autumn compared to summer and butions to the separation ( $F$-to-remove values ranging from 0.05 [ascent] to 0.78 [dive duration]).

With only 2 seasons of dive behaviour in 1995 (summer and autumn), no within-year comparison could be made using the LDA technique (only 2 comparisons, summer and autumn, lead to only 1 discriminant axis). Therefore, we examined the data for 1994 and 1995 combined. The addition of the 1995 data reinforced the seasonal differences observed for 1994. Again, there was significant separation among seasons $\left(F_{14,30}=\right.$ 9.55, $\mathrm{p}<0.0001$ ), with $89 \%$ of the difference among seasons attributable to the first canonical variable. The larger separation between summer and winter versus autumn and winter $\left(F_{7,15}=23.2\right.$ vs $\left.F_{7,15}=8.6\right)$ was maintained, although the disparity was not as pronounced (Fig. 2b). Trip duration $\left(F_{7,15}=17.3\right)$ accounted for the majority of the difference in dive behaviour, with descent rate $\left(F_{7,15}=8.2\right)$ contributing the next highest to the division. The other 5 variables again made low contributions to the separation ( $F$-toremove values ranging from 0.21 [mass] to 2.96 [dive duration]).

The frequency distributions of the IBIs for each of the different seasons (all females combined) were highly skewed, with median IBIs from 4.0 to 6.7 min (Fig. 3). Although the distributions were not as consistently bimodal as those of Boyd (1996), we were able to differentiate an inflexion point by constructing log survivorship curves of the IBIs within each season. The inflexion occurred at 10 to $14 \mathrm{~min}$; therefore, we estimated prey patch encounter rate using a cutoff of IBIs $>10$ min, double that of Boyd (1996). Prey patch encounter rate varied from a minimum mean rate of 2.01 patches $\mathrm{h}^{-1}$ (lower $95 \% \mathrm{CI}=1.81$, upper $95 \% \mathrm{CI}=$ 2.21 ) in winter 1994 to a maximum mean rate of 2.65 patches $\mathrm{h}^{-1}$ (lower $95 \% \mathrm{CI}=2.41$, upper $95 \% \mathrm{CI}=2.88$ ) in summer 1995 (Table 5). Encounter rates never approximated a Poisson distribution (KolgomorovSmirnov 1-sample test, Poisson, mean = lambda, all seasons, $\mathrm{p}<0.001)$. The encounter rate was least in winter (Fig. 4). The greatest distance from the breeding colony in the summer was $78 \mathrm{~km}$, compared with $178 \mathrm{~km}$ in autumn and $162 \mathrm{~km}$ in winter (Fig. 4). Most locations were clustered on the shelf or near the continental slope in summer, with only a single location
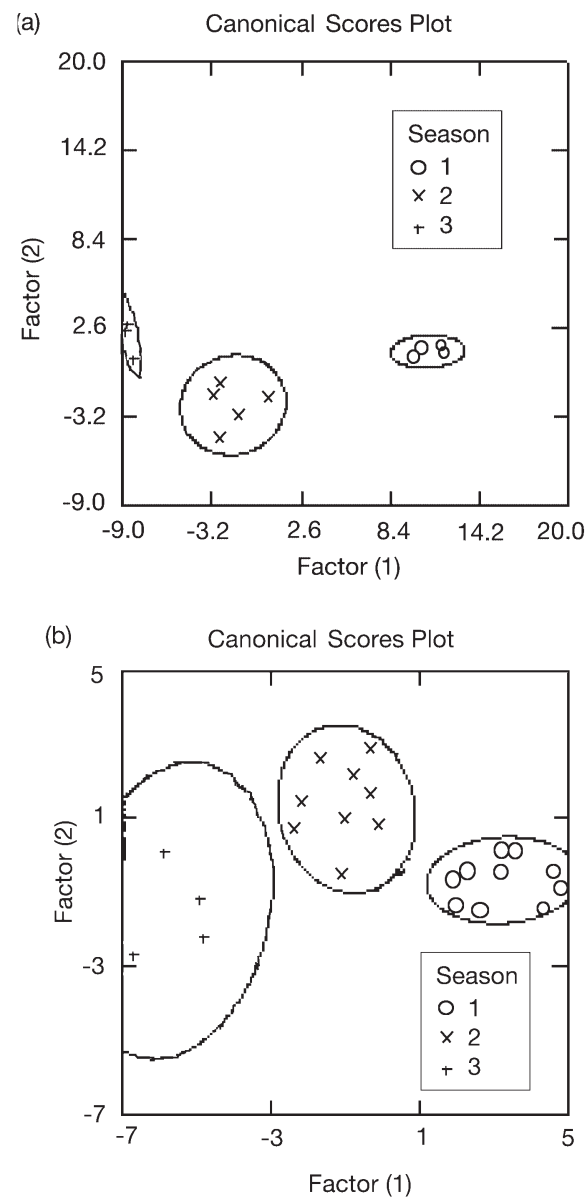

Fig. 2. Linear discriminant analysis for mass, time spent at sea and dive characteristics for individual females (a) in summer, autumn and winter of 1994 and (b) in summer, autumn and winter of 1994 and 1995 combined 

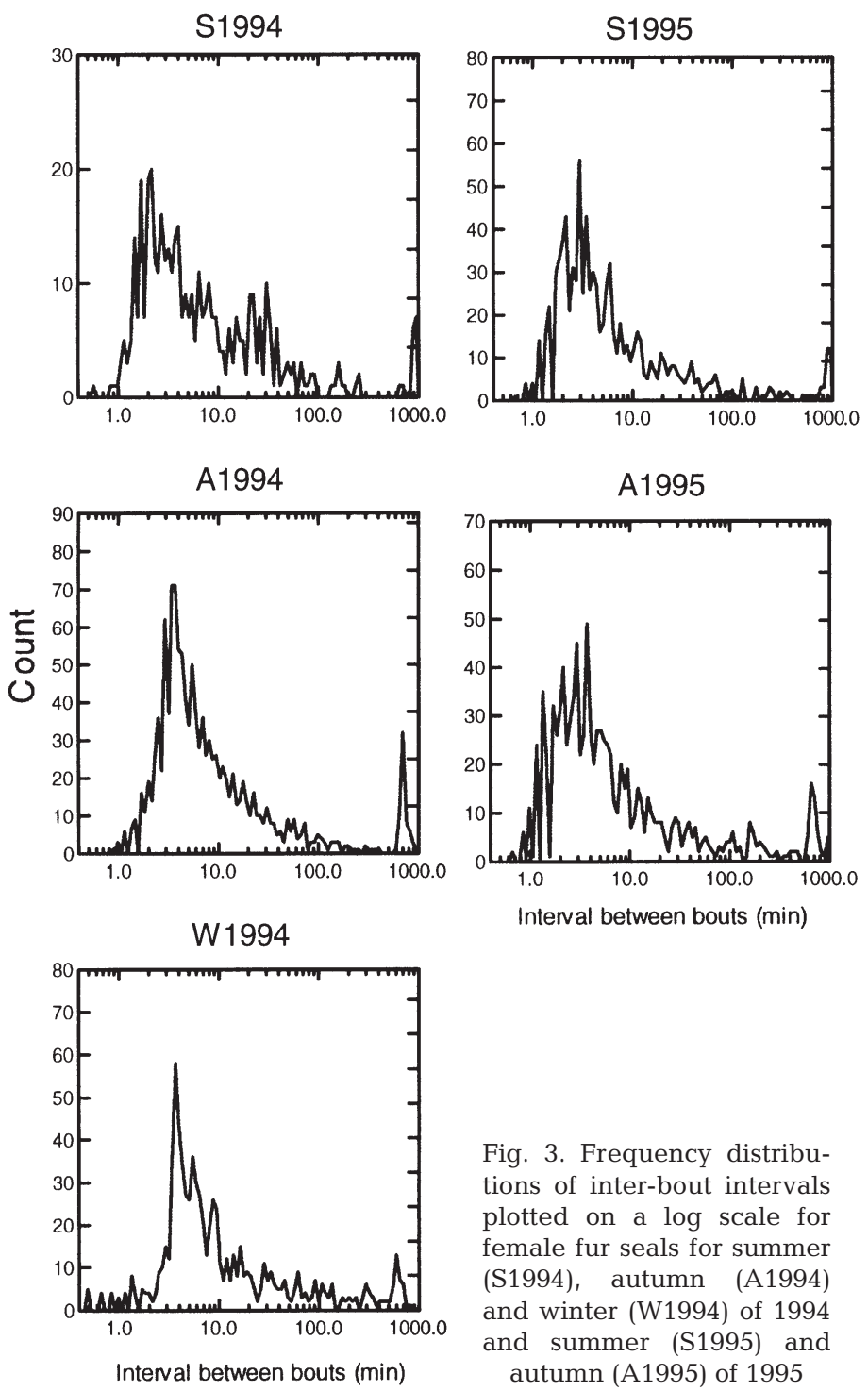

Fig. 3. Frequency distributions of inter-bout intervals plotted on a log scale for female fur seals for summer (S1994), autumn (A1994) and winter (W1994) of 1994 and summer (S1995) and autumn (A1995) of 1995

beyond the slope edge (Table 6). In autumn, female foraging trips took them far beyond the continental slope, with $67 \%$ of locations over deep water $(>1000 \mathrm{~m}$, Table 6). One female in autumn also hauled out during a foraging trip at another fur seal colony, Nugget Point, about $110 \mathrm{~km}$ south-southwest of Otago Peninsula. From the TDR records it appeared that 2 of the inshore locations in autumn occurred during transit to the foraging area, the other was very close to the shelf edge. Offshore locations were recorded when the seals spent extended periods at the surface. In winter, female dive locations were similar to summer. Most locations were received over the continental shelf, with only $6 \%$ of locations, all from a single female, over deep water beyond the continental slope (Table 6). Deep diving by females is consistent with feeding both over the shelf and beyond.
Diet

We collected 690 scats and 166 regurgitates over the course of the 6 seasons (no regurgitates were found in winter 1995, despite extensive searches), with a minimum of 4083 prey items from scats and 591 from regurgitates. The number of taxa (genus and species) detected in scats and regurgitates in each of the 6 seasons of the study ranged from a minimum of 3 (summer 1995) to a maximum of 16 (winter 1994), with a total for the entire study of 22. Proportional biomass was reconstructed as outlined in the 'Materials and methods'. Because it is difficult to compare proportional abundance from prey items passed through in the faeces with those ejected as regurgitates (although see Fea \& Harcourt 1997, Fea et al. 1999), we present their respective contribution to biomass separately. The proportional contribution to biomass of different fish and cephalopod taxa differed by season and between years (Table 7). Arrow squid Nototodarus sloanii was a major contributor $(>10 \%)$ to the diet as assessed exclusively from scats in summer and autumn of both years, but not in winter. Arrow squid were small to medium in summer (mean mass 113 to $382 \mathrm{~g}$ ), but large in autumn (mean mass 300 to $985 \mathrm{~g}$ ). A few, very large squid (mean mass $1.19 \mathrm{~kg}, \mathrm{n}=11$ ) were present in regurgitates in winter 1994, none were present in winter 1995, and only very small beaks (mean mass 16 to $29 \mathrm{~g}$ ) were found in scats in either of the winters (Table 7). Two genera of myctophids Lampanyctodes and Symbolophorus were either individually or together major contributors in every season except winter 1994. Jack mackerel Trachurus spp. and barracouta Thyrsites atun were also major contributors in summer 1994; the former was also of importance in winter 1994. In neither winter was arrow squid an important prey item as measured using scats, nor were myctophids. In both winters, the pink cod, ahuru Auchenocerus punctatus, was a predominant prey species, particularly in 1995, where it made up $65.5 \%$ of biomass. Ahuru and jack mackerel together contributed more than $60 \%$ of prey biomass as assessed by scats in winter 1994 .

Prey biomass determined using regurgitates showed a similar seasonal pattern (Table 7). Regurgitates were found commonly at the colony in summer and autumn of both years (Table 7). Fewer were found in winter 1994 and none in winter 1995 despite extensive searching. The items found in regurgitates are usually larger than those found in scats (Holborrow 2000), and may represent indigestible items too large to pass through the pylorus sphincter. Numerous whole squid are found commonly in fur seal colonies in New Zealand (Harcourt 2001). More than $95 \%$ of the prey biomass recalculated from regurgitates in summer and autumn of both years was composed of squid, but few 
Table 6. Number (\%) of satellite locations over the continental shelf (depth $<250 \mathrm{~m}$ ), at the continental slope (depth 250 to $1000 \mathrm{~m}$ ), and pelagic, beyond the continental slope (depth > $1000 \mathrm{~m}$ ), for female fur seals in 1994

\begin{tabular}{|lrlc|}
\hline Season & Shelf & Slope & Pelagic \\
\hline Summer & $25(89)$ & $2(7)$ & $1(3.5)$ \\
Autumn & $3(20)$ & $2(13)$ & $10(67)$ \\
Winter & $61(90)$ & $3(4)$ & $4(6)$ \\
\hline
\end{tabular}

squid ( $<50 \%$ of prey biomass) were found in winter 1994, and none in winter 1995. New Zealand octopus Octopus maorum made a significant contribution by weight in winter 1994 only.

\section{Inshore trawl data}

Trawl survey data are only available annually, not seasonally. Myctophids are not normally considered in the NIWA database because they have no commercial value. Therefore, we cannot comment on differences in abundance of myctophids between years, at least as measured by trawls. Arrow squid was equally abundant in both years (Table 8). However, for other species there were distinct differences in abundance as assessed by trawl surveys, and their relative abundance did not match consistently that measured by seal diet. One of the most abundant fish species in the region is the barracouta (Hurst \& Bagley 1997). The abundance of barracouta within $200 \mathrm{~km}$ of Fuchsia Gully as assessed by trawl surveys more than doubled in 1995. Yet, barracouta appeared to be significant to the seals only in the summer of 1994. Similarly, the red cod catch was 30 times greater in 1995, yet red cod was only taken in reasonable numbers by the seals in 1994. Even the 3 species of jack mackerel found off Otago, were caught in approximately equal abundance in 1994 and 1995; yet again, the seals took very little in 1995. Ahuru, an important component of the diet in winter in both years, was not caught in either year surveyed.

\section{DISCUSSION}

In this study, we have examined dive behaviour, foraging location and diet of female New Zealand fur seals over the course of $2 \mathrm{yr}$, and in 3 different seasons. The diet of the seals differed significantly among seasons, shifting from a mixed fish and cephalopod based diet, with arrow squid predominant in summer and autumn, to a fish dominated diet in winter. Changes in diet intake were reflected in changes in dive behaviour and foraging location. Diet composition and changes therein did not reflect changes in abundance of fish species as assessed by midwater and benthic trawls in the local area. The seasonal changes in diet, in combi-

Fig. 4. Foraging locations of female fur seals off Otago Peninsula in summer $(n=2)$, autumn ( $\mathrm{n}=3)$ and winter (n $=2$ ) of 1994. Bathymetry in $250 \mathrm{~m}$ isoclines

\section{Summer \\ - FS394s \\ - FS494s}
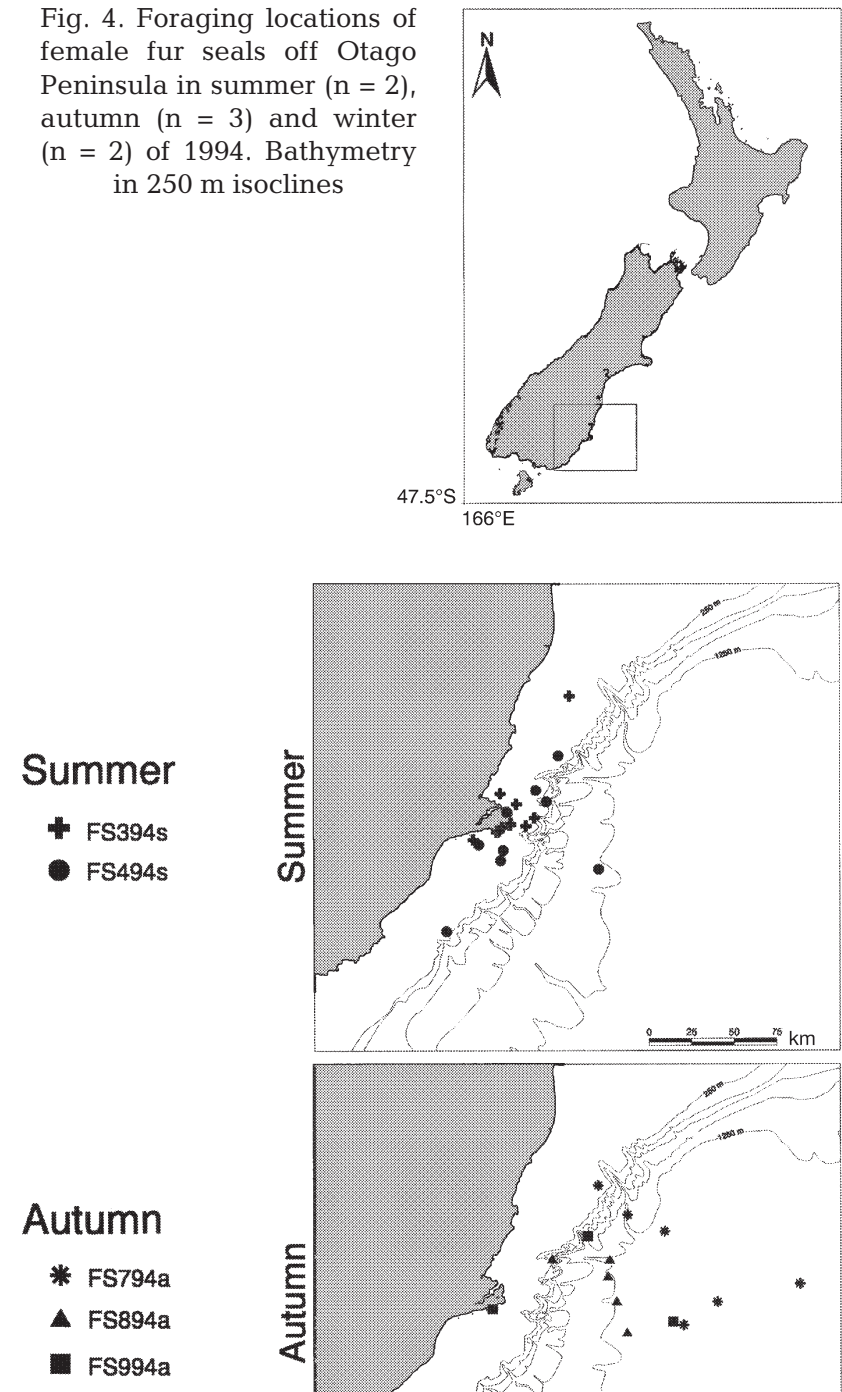
Table 7. Proportional biomass (\%) for prey items found in scats (top) and regurgitates (bottom) for summer 1994 through winter 1995. Only prey that represented a minimum of $5 \%$ in any 1 season is shown

\begin{tabular}{|c|c|c|c|c|c|c|}
\hline Species & ummer 1994 & Autumn 1994 & Winter 1994 & Summer 1995 & Autumn 1995 & Winter 1995 \\
\hline Scats (n) & 97 & 72 & 189 & 114 & 96 & 122 \\
\hline Total number of prey items & 738 & 501 & 1562 & 326 & 146 & 810 \\
\hline Arrow squid Nototodarus sloanii & 19.2 & 57.0 & 7.5 & 32.9 & 10.3 & 8.7 \\
\hline Lampanyctodes hectoris & 12.6 & 9.1 & 6.0 & 18.8 & 8.9 & 0 \\
\hline Symbolophorus & 4.9 & 15.3 & 4.8 & 48.3 & 74.1 & 10 \\
\hline Ahuru Auchenoceros punctatus & 0.0 & 0 & 23.2 & 0 & 0 & 65.5 \\
\hline Red cod Pseudophycis bachus & 6.7 & 7 & 2.5 & 0 & 0.5 & 0.1 \\
\hline Hoki Macruronus novaezelandiae & 0.0 & 7.2 & 0.0 & 0 & 0 & 0 \\
\hline Mackerel Trachurus spp. & 22.3 & 0 & 38.6 & 0 & 0 & 0.8 \\
\hline Tarakihi Nemadactylus macropterus & us $\quad 0.0$ & 1 & 0.6 & 0 & 5 & 0 \\
\hline Barracouta Thyrsites atun & 32.0 & 0 & 0.0 & 0 & 0 & 0 \\
\hline Frostfish Lepidopus caudatus & 0.0 & 0 & 5.2 & 0 & 0 & 0 \\
\hline Blue cod Parapercis colias & 0.0 & 0 & 0.0 & 0 & 0 & 7.8 \\
\hline Biomass (kg) & 13.6 & 4.7 & 7.6 & 2.4 & 1.1 & 4.7 \\
\hline Regurgitates (n) & 48 & 24 & 12 & 49 & 33 & 0 \\
\hline Total number of prey items & 228 & 61 & 19 & 181 & 102 & 0 \\
\hline Arrow squid & 98.6 & 96.1 & 45.3 & 95 & 97 & 0 \\
\hline Octopus Octopus maorum & 0.7 & 3.8 & 54.2 & 5.0 & 3.0 & 0 \\
\hline Biomass (kg) & 59.1 & 61.5 & 29.1 & 72 & 78.4 & 0.0 \\
\hline
\end{tabular}

nation with knowledge of the habitat of the major prey species allow us to examine how female fur seals change their behaviour in response to changes in their environment.

\section{Dive bout structure and IBI}

Boyd (1996) suggested that variation in IBIs by foraging Antarctic fur seals reflect fine and meso-scale variation in krill distribution. We propose that the bout structure seen in this study is a corollary of this, but with significant differences in relation to their more opportunistic diet.

Arrow squid appear to be a seasonally selected prey of New Zealand fur seals and were equally abundant in both years of this study (Table 7; see also Hurst \& Bagley 1997). Arrow squid show a patchy distribution, not dissimilar to krill, although super-aggregations (Veit et al. 1993) have not been reported. Encounter rates, estimated from IBI distribution, were over dispersed, suggesting that the prey patches were associated negatively (i.e. spatial or temporal aversion). Encounter rates were significantly greater in the summer, and this may reflect a high level of abundance of arrow squid patches, combined with a seasonal change in distribution. Between summer and autumn, female foraging trips increased, and the at-sea behaviour suggests that females had to forage much farther from the breeding colony.

In contrast to Antarctic fur seals, which feed predominantly on tightly clumped krill swarms near the surface, New Zealand fur seals forage on mixed aggregations of prey, found primarily at depths $>30 \mathrm{~m}$. The close relationship between IBI and dispersion of prey reported by Boyd (1996) illustrates how the behaviour of a higher predator may be a function of, and therefore an indicator of, prey distribution and abundance. However, the degree to which foraging behaviour of a predator matches that of its prey should also be a function of how reliant the predator is on that prey species. Antarctic fur seals foraging off Bird Island eat predom-

Table 8. Mean catch rate $\left(\mathrm{kg} \mathrm{km}^{-2} \pm \mathrm{SE}\right)$ for the major prey stocks caught in NIWA trawl surveys within a $200 \mathrm{~km}$ radius of Fuchsia Gully in 1994 and 1995

\begin{tabular}{|lcc|}
\hline Species & 1994 & 1995 \\
\hline Arrow squid & $77.9 \pm 29.6$ & $67.8 \pm 27.0$ \\
New Zealand octopus & $1.2 \pm 2.9$ & $0.7 \pm 0.3$ \\
Southern blue whiting & $1.6 \pm 1.6$ & $0.0 \pm 0.0$ \\
Ahuru & 0.0 & 0.0 \\
Red cod & $3.3 \pm 2.7$ & $90.4 \pm 54.7$ \\
Hoki & $17.9 \pm 13.7$ & $15.3 \pm 15.3$ \\
Jack mackerel & 0.0 & 0.0 \\
Trachurus novaezelandiae & $1.4 \pm 0.9$ & $0.4 \pm 0.2$ \\
Jack mackerel & & \\
Trachurus declivis & $23.1 \pm 18.4$ & $17.3 \pm 9.2$ \\
Peruvian jack mackerel & & \\
Trachurus murphyi & $87.0 \pm 29.2$ & $43.8 \pm 19.0$ \\
Tarakihi & $44.3 \pm 20.3$ & $97.5 \pm 42.0$ \\
Barracouta & 0.0 & 0.0 \\
Frostfish & $11.9 \pm 6.5$ & $8.9 \pm 4.4$ \\
Blue cod & 30 & 40 \\
Number of trawls & & \\
& & \\
\hline
\end{tabular}


inantly krill (Croxall \& Pilcher 1984, Reid 1995, Reid \& Arnould 1996). At Bird Island, over 6 consecutive summers, krill was found in $92 \%$ of scats (range 75 to $100 \%$ ), while fish remains were found on average in $<40 \%$ (range 10 to $67 \%$ ) (Reid \& Arnould 1996, McCafferty et al. 1998). Boyd et al. (1994) found no changes in foraging which they could attribute to prey switching, despite measuring foraging behaviour over several years of contrasting abundance. By contrast, New Zealand fur seals consistently forage on a more diverse prey base than Antarctic fur seals. Even when arrow squid make up the bulk of the prey biomass, myctophids and a range of larger fish species persist in significant proportions. The larger fish seen in the diet of the New Zealand fur seal (barracouta, jack mackerel, hoki) are frequently found in mixed aggregations with large arrow squid (Fenaughty \& Bagley 1981, Anderson et al. 2000). All 4 of these species also prey on myctophids. From the fish stomach contents trawled off the east coast of the South Island (C. Lalas pers. comm.). Lampanyctodes hectoris and Symbolophorus spp. ( $S$. barnardi and/or $S$. boops) are predominant in the diets of barracouta and large arrow squid trawled at 120 to $200 \mathrm{~m}$, and Electrona spp. (e.g. E. paucirastra) feature in hoki trawled at 300 to $400 \mathrm{~m}$. Composition and distribution of these mixed aggregations are highly variable, and the bout structure seen with New Zealand fur seals may reflect this. Furthermore, New Zealand fur seals show clear prey shifts between seasons, in part due to changes in size and abundance of arrow squid. There are significant changes in the overall characteristics of fur seal dive behaviour, as well as specific shifts in dive bout type and dive bout structure. These also reflect seasonal changes in prey type.

\section{Seasonal changes in dive behaviour}

New Zealand fur seals off Otago foraged on a diverse range of prey that varied with season. Foraging trips increased in duration as the sea cooled towards winter. Dive behaviour varied in multiple ways. Changes in proportion of bout types indicated that in the summer of both years, as well as autumn 1995, when the seals ate predominantly myctophids and small to medium sized arrow squid, the principle bout type was Shallow. Squid ranged from small juveniles at ca. $5 \mathrm{~g}$ to large adults at ca. $2 \mathrm{~kg}$ and accounted for at least $75 \%$ of the prey biomass. In summer, the shorter IBIs relative to bout duration, corroborated by the elevated patch encounter rate, appear to reflect foraging on patches that were both large and relatively common. Arrow squid are a large, muscular, schooling squid which live for about $1 \mathrm{yr}$ then die after spawning, mostly in autumn, but also in spring (Uozumi \& Ohara
1993). Juvenile arrow squid, which were most common in summer, are found at peak abundance schooling in waters 50 to $100 \mathrm{~m}$ deep (Uozumi \& Ohara 1993), and this corresponds to the large number of Shallow bouts seen in summer. Encounter rate as assessed by the intervals between bouts was highest in these seasons. Combining the short duration of foraging trips, and the short duration of the bouts, with the high encounter rate suggests that they were feeding on small, but frequently encountered prey patches. Overnight foraging trips were mainly seen in summer and may only be feasible when prey patches can be encountered close to the rookery. If the female New Zealand fur seal swims at approximately the same rate at the surface as her Antarctic cousin $\left(1.8 \mathrm{~m} \mathrm{~s}^{-1}\right)$, then we estimate prey patches as being dispersed widely at mean distance of 5.7 to $6.5 \mathrm{~km}$ in summer.

In autumn 1994, foraging trips doubled in length and significant changes in the proportion of bout types occurred. Conversely, although bout types did not change in autumn 1995, foraging trips still lengthened and encounter rates decreased. Large arrow squid predominated in both scats and regurgitates. In 1994, Deep bouts were far the most common type of bout, and in 1995 encounter rates were significantly lower than the warmer season. Satellite tracks placed females over deep water during this period in 1994, which suggests that they were not feeding on benthic organisms on the shelf but diving deep in midwater for large squid. The depth range of large squid from trawls is 150 to $300 \mathrm{~m}$ (Jackson et al. 2000), and the depths used by the female seals in autumn match this closely. The persistence of deep diving throughout the night in autumn (Harcourt \& Davis 1997, Mattlin et al. 1998) suggests either that the diel movements by arrow squid and the other species in these aggregations did not approach the surface, or that the density of patches that did approach the surface was too low to cause a shift in foraging behaviour. Prey patches were more widely dispersed in autumn, with seals likely to swim 11.3 to $15.5 \mathrm{~km}$ between patches.

Dive behaviour, foraging location and encounter rate were also different in winter. Long and Deep bouts were equally prevalent, whereas Shallow was rare. Encounter rates were lower than in any other season. The characteristics of the dive behaviour, in combination with evidence from foraging locations, and diet all suggest that, as arrow squid disappeared from their diet, the fur seals were forced to forage predominantly on the continental shelf. Arrow squid appear to move offshore to deep water to spawn during the winter, and only juveniles are readily available to seals during that period (Uozumi \& Ohara 1993, Uozumi et al. 1995, Fea et al. 1999). Commercial fisheries consider the winterspring period to be the low season for arrow squid 
(Hurst et al. 2000), and it appears that the dive behaviour and feeding habits of the fur seals seen in this study over the winter are also a reflection of the inaccessibility of their major prey item. The mixture of bout types, the low patch encounter rates, and the extended foraging trips suggest that it was more difficult for females to find prey in winter. The duration of IBIs and the coefficient of dispersion suggest that prey remained over-dispersed, and at greater distances than in either of the other seasons, with mean large-scale IBIs of more than $2 \mathrm{~h}$ and the distance between patches averaging $14.7 \mathrm{~km}$. The over-dispersion of prey patches may have important implications for these predators. As prey patches are not clumped, when a seal leaves a patch it is unlikely to find another patch nearby. This implies that fur seals from this population must expend relatively more energy searching for and travelling between prey patches, particularly in seasons when patches are scarce. In winter, the loss of their main prey species, arrow squid, resulted in a wider range of prey being consumed and the changes in bout types presumably reflect this. The many inshore locations (Fig. 2) combined with the change in predominant prey items (Table 6) suggest that despite spending long periods at sea during winter (no OFTs occurred and mean foraging trip length was $\simeq 30 \%$ greater than autumn, Table 1) females focussed considerable efforts in feeding over the shelf area. Ahuru, a shelf-dwelling demersal fish, was an important prey item during both winters, and the benthic sole and flounder were also identified in the winter diet. However, it is unlikely that the seals spent their entire time inshore. The persistence of some lanternfish in scats throughout the year and the presence of a few offshore locations from satellite tagged animals indicate that females also traveled beyond the slope into deeper water. In winter, the equal proportion of 2 different bout types and change in diet composition may indicate a mixture of inshore benthic and offshore pelagic foraging, and that seals were forced to forage widely over the continental shelf.

\section{CONCLUSIONS}

As predicted, the seasonal diving behaviour of female New Zealand fur seals corresponded to shifts in diet inferred from the examination of scats and regurgitates. As opposed to more specialist predators such as Antarctic fur seals, the observed distribution of bouts and IBIs may not provide an index of prey dispersion of generalist predators such as New Zealand fur seals. Instead, seasonal changes in foraging behaviour for this species may indicate changes in prey selection as targeted species become more or less available within the foraging range from the breeding colony. Therefore, the foraging behaviour of generalist predators may not provide as clear a surrogate for local prey abundance and distribution as it does for specialist predators. This ability of generalist predators to 'switch' among selected prey species to meet the energetic requirements of maintenance and reproduction may mask largescale effects. The role of generalist predators as indicators of local prey availability may be unclear in the absence of diet data collected simultaneously.

Acknowledgements. This research was funded by the New Zealand Lottery Board and the University of Otago, and conducted under permit by the Department of Conservation, New Zealand. R.G.H. was supported by a University of Otago Post-Doctoral Fellowship during the study, and by a Royal Society Banks Alecto Fellowship during writing of the paper. Fritz Trillmich provided the TDRs, and we are indebted to both Fritz and John Croxall for continued support. N. Naidoo (Macquarie University, Sydney) assisted us with the bout analysis. We thank Andrew Schulman for collecting attendance data in 1994, Nyree Fea for collecting diet data in 1994, and many other students from the Department of Zoology, University of Otago, for field assistance. Thanks to Ian Boyd, Mark Hindell, Dave Thompson, Fritz Trillmich, and 4 anonymous reviewers for greatly improving earlier drafts of the manuscript.

\section{LITERATURE CITED}

Aebischer NJ, Coulson JC, Colebrook JM (1990) Parallel long-term trends across four marine trophic levels and weather. Nature 347:753-755

Anderson OF, Clark MR, Gilbert DJ (2000) Bycatch and discards in trawl fisheries for jack mackerel and arrow squid, and in the longline fishery for ling, in New Zealand waters. NIWA Tech Rep 74

Antonelis GA, Sinclair EH, Ream RR, Robson BW (1997) Interisland variation in the diet of northern fur seals (Callorhinus ursinus) in the Bering Sea. J Zool 242:435-451

Arnould JPYA, Boyd IL, Rawlins DR, Hindell MA (2001) Variation in matenal provisioning by lactating Antarctic fur seals (Arctocephalus gazella): response to experimental manipulation in pup demand. Behav Ecol Sociobiol 50: 461-466

Beentjes MP (1995) Inshore trawl survey of the Canterbury Bight and Pegasus Bay, May-June 1992 (KAH9205). NZ Fish Rep 55

Bester MN, Laycock PA (1985) Cephalopod prey of the subAntarctic fur seal, Arctocephalus tropicalis, at Gough Island. In: Siegfried WR, Condy PR, Laws RM (eds) Proceedings of the 4th SCAR symposium on Antarctic biology. Springer Verlag, Berlin, p 551-554

Bonadonna F, Lea MA, Guinet C (2000) Foraging routes of Antarctic fur seals (Arctocephalus gazella) investigated by the concurrent use of satellite tracking and time-depth recorders. Polar Biol 23:149-159

Bost CA, Georges JY, Guinet C, Cherel Y and 6 others (1997) Foraging habitat and food intake of satellite tracked king penguins during the austral summer at Crozet Archipelago. Mar Ecol Prog Ser 150:21-33

Boyd IL (1996) Temporal scales of foraging in a marine predator. Ecology 77:426-434

Boyd IL (1999) Foraging and provisioning in Antarctic fur 
seals: interannual variability in time-energy budgets. Behav Ecol 10:198-208

Boyd IL, Croxall JP (1992) Diving behaviour of lactating Antarctic fur seals. Can J Zool 70:919-928

Boyd IL, Croxall JP (1996) Dive durations in pinnipeds and seabirds. Can J Zool 74:1696-1705

Boyd IL, Arnould JPY, Barton T, Croxall JP (1994) Foraging behaviour of Antarctic fur seals during periods of contrasting prey abundance. J Anim Ecol 63:703-713

Boyd IL, Reid K, Bevan RM (1995) Swimming speed and allocation of time during the dive cycle in Antarctic fur seals. Anim Behav 50:769-784

Bradshaw CJA, Davis LS, Lalas C, Harcourt RG (2000) Geographic and temporal variation in the condition of pups of the New Zealand fur seal (Arctocephalus forsteri): evidence for density dependence and differences in the marine environment. J Zool 252:41-51

Brierley AS, Watkins JL, Murray AWA (1997) Inter-annual variability in krill abundance at South Georgia. Mar Ecol Prog Ser 150:87-98

Carey PW (1992) Fish prey species of the New Zealand fur seal (Arctocephalus forsteri, Lesson). NZ J Ecol 16:41-46

Cherel Y, Guinet C, Tremblay Y (1997) Fish prey of Antarctic fur seals Arctocephalus gazella at Isle de Croy, Kerguelen. Polar Biol 17:87-90

Costa DP (1991) Reproductive and foraging energetics of pinnipeds: Implications of life history patterns. In: Renouf D (ed) Behaviour of pinnipeds. Chapman and Hall, New York, p 300-344

Crocker DE, Le Boeuf BJ, Costa DP (1997) Drift diving in female northern elephant seals: implications for food processing. Can J Zool 75:27-39

Croxall JP, Pilcher MN (1984) Characteristics of krill Euphausia superba eaten by Antarctic fur seals Arctocephalus gazella at South Georgia. Br Antarct Surv Bull 63:117-125

Croxall JP, McCann TS, Prince PA, Rothery P (1988) Reproductive performance of seabirds and seals at South Georgia and Signy Island, South Orkney Islands, 1976-1987: implications for southern ocean monitoring studies. In: Sahrhage D (ed) Antarctic Ocean and resources variability. Springer Verlag, Berlin, p 261-285

Daneri GA, Carlini AR (1999) Spring and summer predation on fish by the Antarctic fur seal, Arctocephalus gazella, at King George Island, South Shetland Islands. Can J Zool 77:1157-1160

Dellinger T, Trillmich F (1999) Fish prey of the sympatric Galapagos fur seals and sea lions: seasonal variation and niche separation. Can J Zool 77:1204-1216

Dix B (1993) Population changes and diet preferences of the New Zealand fur seal Arctocephalus forsteri in Eastern Cook Strait. MSc thesis, Victoria University of Wellington

Duhamel G, Koubbi P, Ravier C (2000) Day and night mesopelagic fish assemblages off the Kerguelen Islands (Southern Ocean). Polar Biol 23:106-112

Fea N, Harcourt R (1997) Assessing the use of faecal and regurgitate analysis as a means of determining fur seal diet. In: Hindell M, Kemper C (eds) Marine mammal research in the Southern Hemisphere. Vol 1: Status, ecology and medicine. Surrey Beatty and Sons Ltd, Chipping Norton, p 143-150

Fea N, Harcourt R, Lalas C (1999) Seasonal variation in the diet of New Zealand fur seals (Arctocephalus forsteri) on Otago Peninsula, New Zealand. Wildl Res 26:147-160

Fedak MA (1986) Diving and exercise in seals: a benthic perspective In: Brubakk AO, Kanwisher J, Sundnes G (eds) Diving in animals and man. Tapir, Trondheim, p 11-32

Fedak MA, Thompson D (1993) Behavioural and physio- logical options in diving seals. Symp Zool Soc Lond 66: 333-348

Fenaughty JM, Bagley NW (1981) W. J. Scott New Zealand trawl survey South Island east coast. NIWA Tech Rep 157

Ferreira SM, Bester MN (1999) Chemical immobilisation, physical restraint, and stomach lavaging of fur seals (ArCtocephalus spp.) at Marion Island. S Afr J Wildl Res 29: $55-61$

Filin AA, Gorchinsky KV, Kiseleva KM (1990) Biomass of myctophids in the Atlantic Sector of the southern ocean as estimated by acoustic surveys. CCAMLR Select Sci Papers $417-432$

Gales NJ, Cheal AJ (1992) Estimating diet composition of the Australian sea lion (Neophoca cinerea) from scat analysis: an unreliable technique. Wildl Res 19:447-456

Gales R, Pemberton D, Lu CC, Clarke MR (1993) Cephalopod diet of the Australian fur seal: variation due to location, season and sample type. Aust J Mar Freshw Res 44: $657-671$

Gentry RL (1998) Behavior and ecology of the Northern fur seal. Princeton Univ Press, Princeton, NJ

Gentry RL, Kooyman GL (1986a) Methods of dive analysis. In: Gentry RL, Kooyman GL (eds) Fur seals: maternal strategies on land and at sea. Princeton University Press, Princeton, NJ, p 28-40

Gentry RL, Kooyman GL (1986b) Fur seals: maternal strategies on land and at sea. Princeton University Press, Princeton, NJ

Georges JY, Guinet C (2000) Maternal care in the Subantarctic fur seal on Amsterdam Island. Ecology 81:295-308

Georges JY, Bonadonna F, Guinet C (2000a) Foraging habitat and diving activity of lactating subantarctic fur seals in relation to sea-surface temperatures at Amsterdam Island. Mar Ecol Prog Ser 196:291-304

Georges JY, Tremblay Y, Guinet C (2000b) Seasonal diving behaviour in lactating subantarctic fur seals on Amsterdam Island. Polar Biol 23:59-69

Goldsworthy SD (1999) Maternal attendance behaviour of sympatrically breeding Antarctic and subantarctic fur seals, Arctocephalus spp., at Macquarie Island. Polar Biol 21:316-325

Goldsworthy SD, Hindell MA, Crowley HM (1997) Diet and diving behaviour of sympatric fur seals Arctocephalus gazella and A. tropicalis at Macquarie Island. In: Hindell $M$, Kemper C (eds) Marine mammal research in the Southern Hemisphere. Vol 1: Status, ecology and medicine. Surrey Beatty and Sons Ltd, Chipping Norton, p 151-163

Green K, Burton HR, Williams R (1989) The diet of Antarctic fur seals Arctocephalus gazella during the breeding season at Heard Island. Antarct Sci 1:317-324

Green K, Williams R, Burton HR (1991) The diet of Antarctic fur seals during the late autumn and early winter around Heard Island. Antarct Sci 3:359-361

Guinet C, Koudil M, Bost CA, Durbec JP, Georges JY, Mouchot MC, Jouventin P (1997) Foraging behaviour of satellite tracked king penguins in relation to sea-surface temperature at Crozet Archipelago, a study during three austral summers. Mar Ecol Prog Ser 150:11-20

Harcourt RG (2001) New Zealand fur seal. Advances in mammalogy in New Zealand 1990-2000: Pinnipedia. J R Soc NZ Spec Issue 31:135-141

Harcourt RG, Davis LS (1997) The use of satellite telemetry to determine fur seal foraging areas. In: Hindell M, Kemper $\mathrm{C}$ (eds) Marine mammal research in the Southern Hemisphere. Vol 1: Status, ecology and medicine. Surrey Beatty and Sons Ltd, Chipping Norton, p 137-142 
Harcourt RG, Schulman A, Davis LS, Trillmich F (1995) Summer foraging by lactating female New Zealand fur seals (Arctocephalus forsteri) off Otago Peninsula, New Zealand. Can J Zool 73:678-690

Harcourt RG, Bradshaw CJ, Davis LS (2001) Annual variation in foraging by a generalist predator, the New Zealand fur seal (Arctocephalus forsteri). Wildl Res 28:599-606

Hindell MA, Slip DJ, Burton HR (1991) The diving behaviour of adult male and female elephant seals, Mirounga leonina (Pinnipedia: Phocidae). Aust J Zool 39:595-619

Holborrow J (2000) The diet of New Zealand fur seals (Arctocephalus forsteri) in southern New Zealand. MSc thesis, University of Otago, Dunedin

Hurst RJ, Bagley NW (1997) Trends in Southland trawl surveys of inshore and middle depth species 1993-1996. NZ Fish Tech Rep 50

Hurst RJ, Bagley NW, Anderson OF, Francis MP, Griggs LH, Clark MR, Paul LJ, Taylor PR (2000) Atlas of juvenile and adult fish and squid distributions from bottom and midwater trawls and tuna longlines in New Zealand waters. NZ Fish Tech Rep 84

Jackson GD, Shaw AGP, Lalas C (2000) Distribution and biomass of two squid species off southern New Zealand; Nototodarus sloanii and Moroteuthis ingens. Polar Biol 10: 699-705

Jouventin P, Weimerskirch H (1990) Long-term changes in seabird and seal populations in the Southern Ocean. In: Kerry KR, Hempel G (eds) Antarctic ecosystems: ecological change and conservation. Springer Verlag, Berlin, p 208-213

Kann LM, Wishner K (1995) Spatial and temporal patterns of zooplankton on baleen whale feeding grounds in the southern Gulf of Maine. J Plankton Res 17:235-262

Klages NTW, Bester MN (1998) Fish prey of fur seals Arctocephalus spp at subantarctic Marion Island. Mar Biol 131: 559-566

LeBoeuf BJ, Costa DP, Huntley AC, Feldkamp SD (1988) Continuous, deep diving in female northern elephant seals, Mirounga angustirostris. Can J Zool 66:446-458

Lindstrom U, Harbitz A, Haug T, Nilssen KT (1998) Do harp seals Phoca groenlandica exhibit particular prey preferences? ICES J Mar Sci 55:941-953

Manly BFJ (1997a) Randomization bootstrap and Monte Carlo methods in biology. Chapman and Hall, London

Manly BFJ (1997b) RT a program for randomization testing. West Inc, Cheyenne

McCafferty DJ, Boyd IL, Walker TR, Taylor RI (1998) Foraging responses of Antarctic fur seals to changes in the marine environment. Mar Ecol Prog Ser 166:285-299

Martin P, Bateson P (1986) Measuring behaviour. Cambridge University Press, Cambridge

Mattlin RH, Gales NJ, Costa DP (1998) Seasonal dive behaviour of lactating New Zealand fur seals (Arctocephalus forsteri) Can J Zool 76:350-360

Mori Y (1998) The optimal patch use in divers: optimal time budget and the number of dive cycles during bout. J Theor Biol 190:187-199

Editorial responsibility: Otto Kinne (Editor), Oldendorf/Luhe, Germany
Nicol S, Pauly T, Bindoff NL, Wright S, Thiele D, Hosie GW, Strutton PG, Woehler E (2000) Ocean circulation off east Antarctica affects ecosystem structure and sea-ice extent. Nature 406:504-507

Ponganis PJ, Gentry RL, Ponganis EP, Ponganis KV, Kooyman GL, Trillmich F (1990) Swimming velocities in otariids. Can J Zool 68:2105-2112

Reid K (1995) The diet of Antarctic fur seals (Arctocephalus gazella Peters 1875) during winter at South Georgia. Antarct Sci 7:241-249

Reid K, Arnould JPY (1996) The diet of Antarctic fur seals (Arctocephalus gazella Peters 1875) during the breeding season at South Georgia. Polar Biol 16:105-114

Siegel V, Kalinowski J (1994) Krill demography and smallscale processes: a review. In: El-Sayed EZ (ed) Southern Ocean ecology: the BIOMASS perspective. Cambridge Univ Press, Cambridge, p 145-164

Slip DJ, Hindell MA, Burton HR (1994) Diving behavior of southern elephant seals from Macquarie Island: an overview. In: Le Boeuf BJ, Laws RM (eds) Elephant seals: population ecology, behavior, and physiology. University of California Press, Berkeley, p 253-270

Stephens DW, Krebs JR (1986) Foraging theory. Princeton Univ Press, Princeton, NJ

Tate ML (1981) The autumn-winter diet of the New Zealand fur seal Arctocephalus forsteri (Lesson) with special reference to its cephalopod prey. Diploma of Wildlife Management thesis, University of Otago, Dunedin

Trillmich F (1990) The behavioral ecology of maternal effort in fur seals and sea lions. Behaviour 114:3-20

Trillmich F, Ono KA (1991) Pinnipeds and El Niño: responses to environmental stress. Springer-Verlag, Berlin

Tynan CT (1998) Ecological importance of the Southern Boundary of the Antarctic Circumpolar Current. Nature 392:708-710

Uozumi Y, Ohara H (1993) Age and growth of Nototodarus sloanii (Cephalopoda: Oegopsida) based on daily increment counts in statoliths. Nippon Suisan Gakkaishi 59:1469-1477

Uozumi Y, Koshida S, Kotoda S (1995) Maturation of arrow squids Nototodarus gouldi and N. sloanii with age in New Zealand waters. Fish Sci 61:559-565

Veit RR, Silverman ED, Everson I (1993) Aggregation patterns of pelagic predators and their principal prey, Antarctic krill, near South Georgia. J Anim Ecol 62:551-564

Watkins JL, Murray AWA (1998) Layers of Antarctic krill, Euphausia superba: Are they just long krill swarms? Mar Biol 131:237-247

White WB, Peterson RG (1996) An Antarctic circumpolar wave in surface pressure, wind, temperature and sea-ice extent. Nature 380:699-702

Williams R, de la Mare WK (1995) Fish distribution and biomass in the Heard Island zone (Division 58.5.2). CCAMLR Sci 2:1-20

Zamon JE, Greene CH, Meir E, Demer DA, Hewitt RP, Sexton S (1996) Acoustic characterization of the three-dimensional prey field of foraging chinstrap penguins. Mar Ecol Prog Ser 131:1-10

Submitted: May 11, 2001; Accepted: August 27, 2001

Proofs received from author(s): February 1, 2002 